Foto I

\title{
LEITE DE CÁLCIO
}

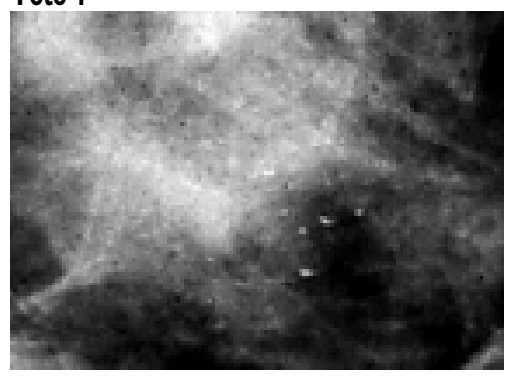

Foto la
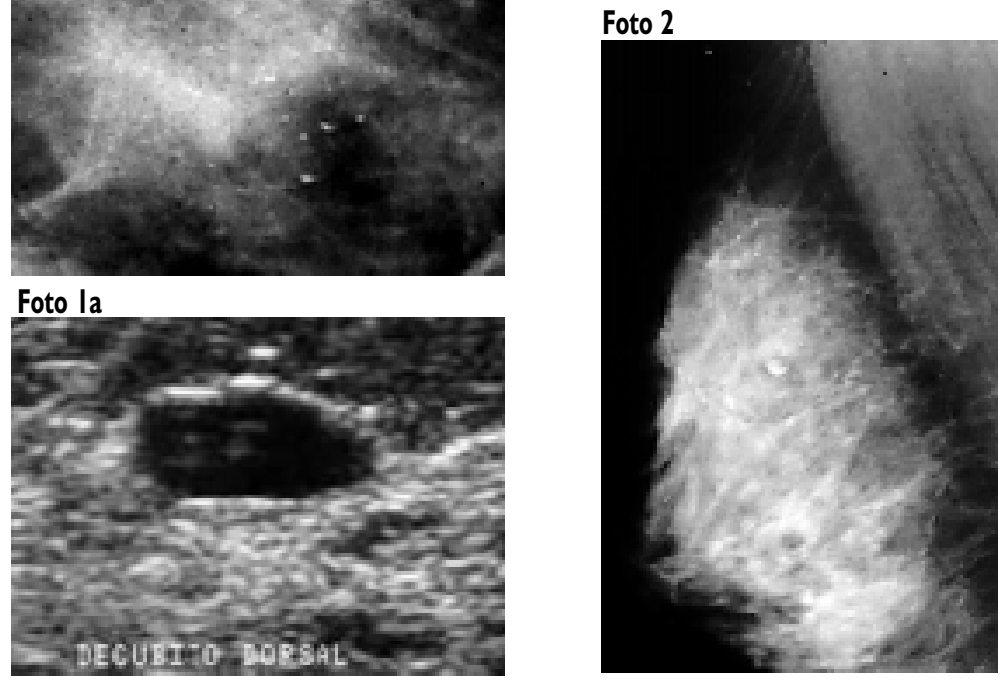

Foto 3

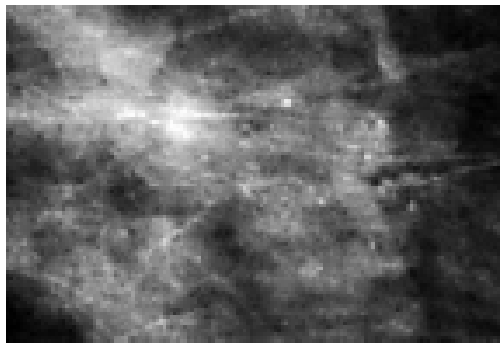

Microcalcificações são achados comuns na mamografia e, por definição, são estruturas com tamanho igual ou menor a 0,5 mm. De forma bastante grosseira, assumimos que partículas pequenas sugerem malignidade e partículas maiores são mais sugestivas de benignidade.

A detecção da sua ocorrência é extremamente importante, principalmente por que podem constituir a única alteração radiológica visível na mamografia. Esse achado mamográfico é encontrado em cerca de $40 \%$ dos casos de câncer em lesões não-palpáveis' e pode representar o sinal mais precoce de malignidade.

O diagnóstico mamográfico constitui-se de atividade de detetive; um especialista habilitado e treinado é necessário e, longe de ser tarefa trivial, muitos fatores de técnica estão relacionados e devem ser considerados para esse diagnóstico. É imperativo adotar-se incidências adicionais com ampliação das microcalcificações para avaliação da sua morfologia devido às pequenas dimensões.

O leite de cálcio, alteração mamográfica descrita como tipicamente benigna (BI-RADS ${ }^{\text {TM }}$ II), apresenta na mamografia um aspecto de meia-lua (foto I) ou em xícara de chá, ${ }^{2,3}$, que é influenciado pela força da gravidade, correspondendo à precipitação de cristais de cálcio no interior de estruturas micro ou macro císticas dilatadas (foto la). Portanto, na incidência em perfil absoluto ou médio-lateral oblíqua (foto 2) (feita com a mama pendente, sendo sustentada por estar comprimida lateralmente) essa morfologia é tipicamente benigna, diferente da aparência esférica com margem esfumaçada ou amorfa vista na projeção crânio-caudal (feita com a mama comprimida, apoiada sobre a placa de acrílico).

Se somente o estudo complementar com ampliação na incidência crânio-caudal for feito, o diagnóstico de leite de cálcio não poderá ser feito e, pelo contrário, a morfologia amorfa relaciona-se ao maior grau de suspeição para malignidade (foto 3). Na análise de microcalcificações pode-se utilizar a classificação morfológica, de valor crescente, proposta por Michèle Le Gal et al. ${ }^{4}$, como orientação (Tabela I).

\begin{tabular}{|ccc|}
\hline & Tabela I - Classificação morfológica de Michèle Le Gal (1984) \\
\hline Tipo & Microcalcificações - Morfologia & \% de malignidade \\
\cline { 2 - 3 } TIPOI & anulares, redondas, discóides, com centro lucente & todas são benignas \\
TIPOII & redondas, isodensas, uniformes & $22 \%$ são malignas \\
TIPOIII & puntiformes, tipo "poeira", difíilidentificação & $40 \%$ são malignas \\
TIPOIV & irregulares, poliédricas, tipo "grão de sal" & $66 \%$ são malignas \\
TIPOV & vermiculares, ramificadas, emforma de letras & todas são malignas \\
\hline
\end{tabular}

Trabalho realizado no ambulatório de Raio X - Setor de mamografia- departamento de Diagnóstico por Imagem da Referências Escola Paulista de Medicina - Universidade Federal de São Paulo, São Paulo, SP.

I. Marini C, Traino C, CilottiA, Roncella M, Campori G, Bartolozzi C. Differentiation of benign and malignant breastmicrocalcifications: mammography versus mammographysonography combination. Radiol Med (Torino) 2003; 105(I-2): 17-26.

2. American College of Radiology. Breast imaging reporting and data system (BI-RADS). 3rd ed. Reston: American College of Radiology; 1998.

3. Scaranelo AM. Aprendendo a relatar mamografia. São Paulo: Livraria Editora Santos; 2002. p.27-31.

4. Le Gal M, Chavanne G, Pellier D. Valeur diagnostique des microcalcifications groupées découvertes par mammographies. Bull Cancer 1984; 71:57-64. 